\title{
Ubiquitous Information System to Solve Farmers Problems
}

\author{
Prabhat Kumar Ranjan \\ Department of Comp Sci \& Engg \\ Aarupadai Veedu Inst of Tech \\ Paiyanoor, O M Road \\ Chennai, 603104
}

\author{
Akash Deep \\ Department of Comp Sci \& Engg \\ Aarupadai Veedu Inst of Tech \\ Paiyanoor, O M Road \\ Chennai, 603104
}

\author{
R. Ponnusamy \\ Department of Comp Sci \& Engg \\ Aarupadai Veedu Inst of Tech \\ Paiyanoor, O M Road \\ Chennai, 603104
}

\begin{abstract}
In this paper attempt has been made to solve the farmers problems of getting suitable information required for cultivation. In this approach we use the ubiquitous learning to solve this problem. In this system the farmers could access the server and download problem solution in two modes through wireless communication devices in line with J2ME. It is very beneficial because Ubiquitous Information System has an increasing trend as the coming forth of more new media and instructional ideas. U-information system focuses on the combination of getting environment and substance space, emphasizing the getting Information can be happen as seeing, hearing, reading, or apperceiving whenever the farmer wanted. A farmer can do their work and get the information simultaneously without wasting time. Also, the farmers can make the cultivation very effective.
\end{abstract}

The full text of the article is not available in the cache. Kindly refer the IJCA digital library at www.ijcaonline.org for the complete article. In case, you face problems while downloading the full-text, please send a mail to editor at editor@ijcaonline.org 